\title{
PSYCHOLOGICAL CHARACTERISTICS OF REMEDIAL TEACHERS OF DIFFERENT ALTRUISM LEVELS
}

\author{
Dina Shulzhenko, Professor of Psychology \\ Faculty of Correctional Pedagogy and Psychology \\ National University of Pedagogy \\ 9, Pyrohov St., Kyiv Ukraine \\ KHRISTINA SAYKo \\ Faculty of Correctional Pedagogy and Psychology \\ National University of Pedagogy \\ 9, Pyrohov St., Kyiv Ukraine \\ E-mail address: tvir@meta.ua
}

\begin{abstract}
The authors of this paper studied psychological characteristics of remedial teachers with different altruism levels. Altruism is a motive to render assistance to anyone not consciously related to one's own selfish interests. Subjectively it manifests itself in sympathy, being oriented towards helping others. Altruism is opposed to selfishness, which is incompatible with disinterested concern for the welfare of others and willingness to sacrifice personal interests for them. The main driving force behind altruistic behaviour is a drive to improve the situation of others rather than expecting some reward. In psychology, altruism is considered as a system of personality value priorities in which interests of another person or social community are a central motive and a moral evaluation criterion.

Keywords: altruism, selfishness, sociability orientation, self-assertion orientation, activity orientation, value priorities, character qualities.

The aim of our study was to identify empirical psychological characteristics of remedial teachers. The term of "altruism" was introduced by Auguste Comte, who formed the "vivre pour autre" principle that means "to live for others". The scientist distinguished instinctive altruism combining an individual and a clan then destroyed by civilization, which is inherent to animals and altruism that appears and develops within it and finally turns into spontaneous, inherited quality that is common to all people (Andreyeva, 1998, p. 328).

There are different altruism definitions: it is defined as love and concern for others; a drive for the welfare of others without any benefit for yourself; a tendency to unselfishly sacrifice yourself to others (Andreyeva, 1998, p. 329). This notion is closely related to the term of "prosocial behaviour" which is general in nature and characterizes different forms of behaviour made in the interests of various social objects as opposed to the behaviour pursuing personal interests.

In the history of psychology, there are several points of view to explain the nature of altruism (Andreyeva, 1998, pp. 334-335):

Altruistic standards. They imply a need to give back and they are a standard of social responsibility. That is why, if one person is dependent on another one
\end{abstract}


to achieve his goal, then the other one should help him. Following this standard depends on the actualization degree. Actualization is determined by past human experience. Altruistic "standard of social responsibility" (a drive to help everybody) is actualized if previous individual help was positive or absent, and "good for good standard" is actualized if it was negative.

Within behaviourism altruism is considered as the behaviour caused by negative or positive empathic reinforcement (i.e. disappearance of unpleasant feeling that arises at the sight of another person's suffering or appearance of pleasant feeling at the sight of a person's relief from his suffering). In this case altruism is identified with selfish behaviour. Weiss believes an altruistic act to be of self reinforced meaning.

In psychoanalysis altruism is considered as a drive to reduce an inherent human feeling of guilt through disinterested action. Based upon this hypothesis, authors supposed that the research subjects who violated a specific rule are to be more inclined to altruistic behaviour. Similar results were obtained in the study of Samuel B. Harris The Moral Landscape: How Science Can Determine Human Values (2010). Thus, Catholics going to confession donate much more money to charity than believers having already confessed. The authors explain this phenomenon as guilt feeling reduction after confession.

The problem of altruism is widely covered in the literature and represented in the works of various authors. Analysing theoretical approaches in volunteer system interpreting, you can distinguish the following main approaches (Hapon, 2008, p. 175):

The first approach has been developed in the course of sociological social psychology. It is supported by the concept of symbolic interactionism of Herbert Blumer. According to his research, society is defined as a symbolic interaction of individuals. Humans act towards things on the basis of the meanings they have for them. The meaning of things arises out of the social interactions one has with one's fellows.

The second approach is sociological and it is represented by Alfred Schutz and Robert Putnam. We agree with the ideas of this approach claiming that society is developing in the spiritual interaction between humans. In the course of sociological approach altruism is considered as functioning of two social standards: mutuality and social responsibility. The standard of social responsibility implies that humans are expected to help those who depend on them without requiring any return in the future.

The third approach to altruism is suggested by evolutionary psychology. Within evolutionary theory disinterested behaviour is explained by such innate mechanisms as clan defense and search for mutual benefit. This approach is represented by a psychological theory of social exchange. According to this theory, people exchange not only material values (belongings, money etc.) but also social values such as friendship, services, information and status. Even so, people try to minimize their expenses and to get maximum possible rewards.

the concept of altruism as disguised selfishness. Rewards that motivate rendering assistance can be both external and internal. People give something to get 
material or psychological rewards later. Sympathy expressed to another person can hide inner self-reward - positive self-perception. Considering the problem of altruism, a researcher Pitirim Sorokin in his work Contemporary sociological theories (1992) uses two notions: eros and agape. A self-centred eros adheres to the following principles as "live and let live", "help others to help you more". Agape-love is opposed to eros; it's unselfish love able to give and not to take anything in return (Hapon, 2008, p. 176). If the concept of Pitirim Sorokin serves as illustration, volunteering belongs to the second type of altruism. A volunteer gets a psychological reward doing his job but what is important is that he does not make it his aim at the subjective level; getting satisfaction from something done is an indirect result of the basic drive - to help people, to do something useful.

the concept of altruism as a human state of mind. A social psychologist Daniel Batson (2011) found willingness to help others to be a result of two different personal positions. The researcher assumes that a person can be disturbed by his own deep psychological states (remorse etc.) and empathic experience. Helping another person enables a person to find a sense of self-equilibrium (Hapon, 2008, p. 175). When analysing the theories mentioned above, it is asserted that rendering assistance can be caused by the following: (1) frank or implicit selfishness (to help in order to get a reward, or to avoid punishment); (2) mental discomfort (to help in order to regain psychical equilibrium); (3) empathy (to find a sense of equilibrium by having comforted another person). Altruism or helping others is a behavioural quality which is opposed to selfishness. An altruistic person is willing to help unselfishly, expecting nothing in return.

Altruistic motivation is always an intrinsic personal meaning motivation described by meaning-making motive. Among intrinsic motivational mechanisms of altruistic content, two motives, meaning determinants of altruism, should be distinguished as the moral duty motive and the sympathy motive.

Analysis of theoretical works and experimental research data of domestic and foreign psychologists on altruistic behaviour confirms actuality of altruistic motives as independent psychic formations. However, revealing the content of disinterested help motive or welfare-for-others motive, some researchers interpret this motive as interiorization of an altruistic standard, and others as manifestation of effective empathy or sympathy. Thus, there are two main approaches to understanding the motivational nature of altruistic behaviour as (Aronson, 2002, p. 125):

personal normative (by moral norms and personal beliefs)

emotional (by analysing the role of altruistic emotions - empathy, compassion, implementation of sympathy through altruistic behaviour). Most researchers implement either individual normative or emotional approach to the analysis of motivational determinants of altruistic behaviour, while the mentioned approaches are mostly mutually exclusive. The attempts to synthesize both aspects seem to be promising (Schwartz, 2004; Heckhausen, 2008; Karylowski, 1982).

As for the emotional mechanisms, we should distinguish between the contextual effect of altruistic emotional experience on helping behaviour and enduring emotional attitude towards situations of needs and a poor state of another person which serves as a specific motive formed on the emotional basis (sympathy, empathy). 
To successfully solve important tasks a remedial teacher should have certain personal qualities without which working with children with special educational needs seems to be impossible. They are: teaching sensitivity expressed in the ability to detect any changes in mental activity, behaviour, general condition of a child by even the smallest signs and to adequately respond to such changes (1); patience and persistence in achieving set goals in working with children with developmental disorders (2); firmness, consistency, self-discipline and sense of tact in teaching (3). Psychological requirements for specialists who work with individuals with special educational needs including psychological willingness of a personality for this work. This willingness can be considered as integrated quality of a personality including a system of motivation, knowledge, skills, certain experience, personal qualities that ensure successful activity.

To make inclusive teaching more successful, a teacher should acquire necessary knowledge and skills, such as (Adolph, 1998, pp. 15-16):

- to have complete information on medical history, be aware of main types of mental and physical developmental disorders of children;

- to learn a state of attention, fatigability, working rate of each child;

- to consider a state of hearing, sight and motility;

- to learn to observe children and assess their developmental dynamics (i.e. epigenetics) in the course of studies;

- to adapt curricula, methods, visual aids and environment to special needs of children;

- to create optimal conditions for communication, to favour friendly relations and team forming among children;

- to form children's experience of relationship in society, skills to adapt to the social environment;

- to respect children and their parents.

A psychological research involved 70 individuals: 35 remedial teachers (5 men and 30 women) of a boarding school № 6 for children with difficult speech disorders and 35 teachers of comprehensive schools № 67 and № 55 (11 men and 24 women). The following methods were used: methods of diagnosing "altruismselfishness" personal attitude, methods of diagnosing personality orientation of Bernard Bass (1967), a test to identify emotional orientation, methods of diagnosing psychosocial personality attitude in the motivational need sphere of Olha Potyomkina (2005), methods of «Human values» of Milton Rokeach and methods of multivariate personality research of Raymond Cattell (1950). According to M. Rokeach «Human values» methods, it was determined that among comprehensive school teachers knowledge value (ability to expand one's education, views, personal culture, intellectual development) takes the first place, education value (breadth of knowledge, considerable personal culture) takes the second place, selfassurance value (inner harmony, freedom from self-contradictions and doubts) takes the third place and breadth of views value (skill to understand another's point of view, respect other tastes, customs and habits) takes the fourth place (see Fig. 1.1.). 
Fig. 1.1. The results of percentage analysis under M. Rokeach „Human values” methods in the group of comprehensive school teachers.

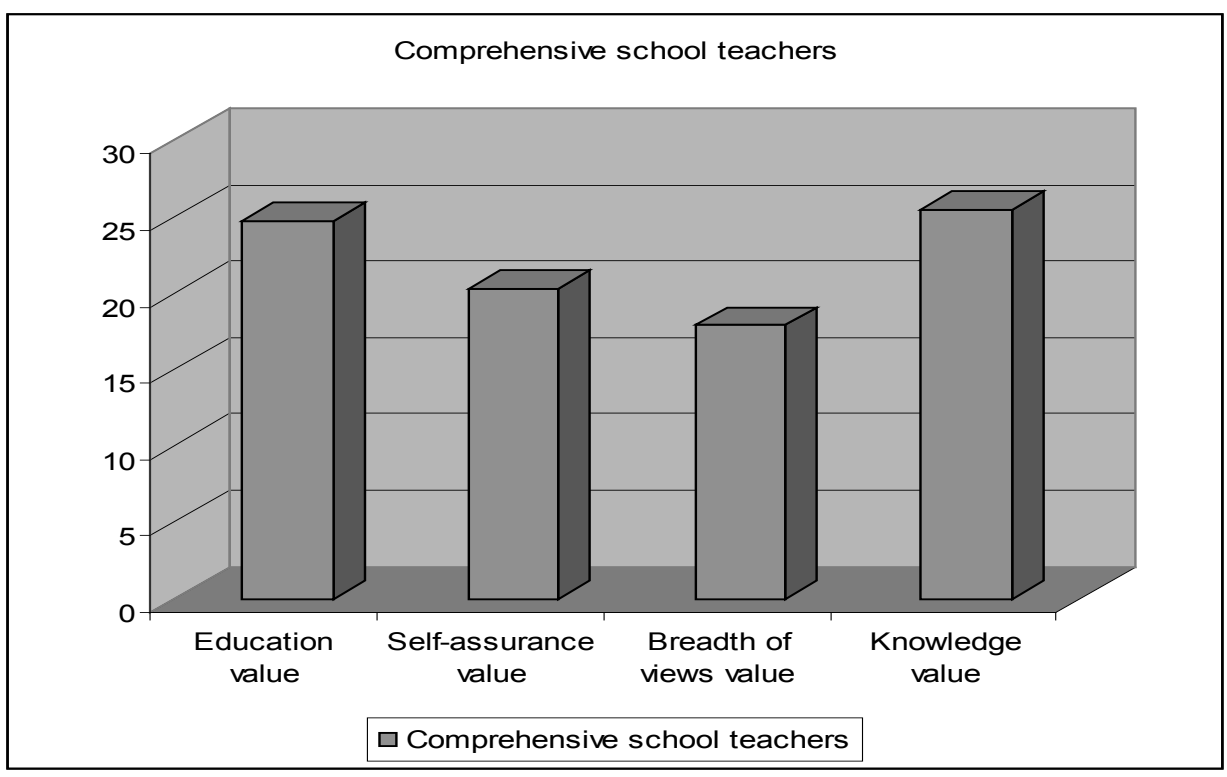

Source: Authors`research.

Among remedial teachers tolerance value (to other people's opinions and views, ability to forgive others their mistakes) takes the first place, development value (self-perfection, permanent physical and spiritual improvement) takes the second place, strong will value (skill to insist on one's own way, to face difficulties) takes the third place and independence value (ability to act on one's authority and in a determined way) takes the fourth place (see Fig. 1.2.).

Fig. 1.2. The results of percentage analysis under M. Rokeach «Human values» methods in the group of remedial teachers.

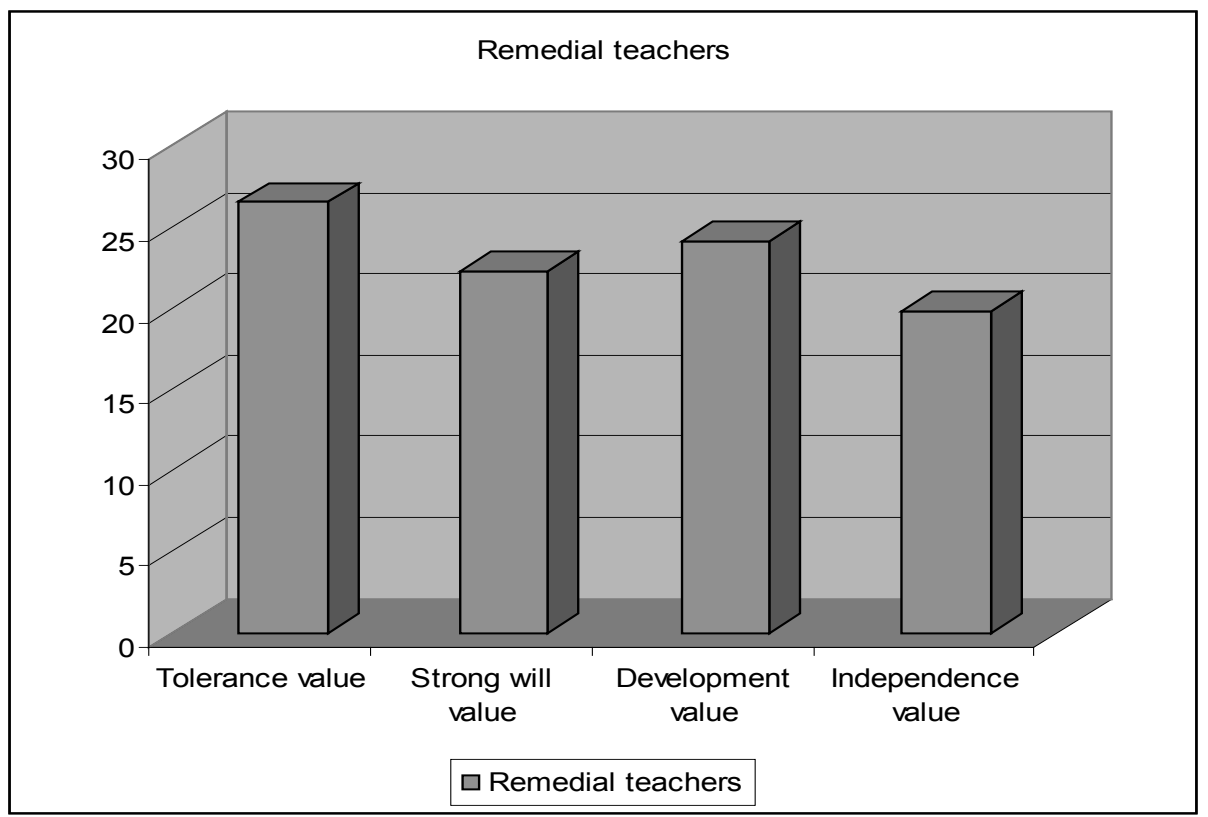

Source: Authors`research. 
According to the results of $\mathrm{R}$. Cattell multivariate personality research methods, it was determined that among remedial teachers the following predominate: sociability, openness, readiness to cooperate, attention to others, superior intelligence, high mental abilities, shrewdness, emotional stability, a drive to dominate, reasoning, self-analysis, high rule-consciousness, assertiveness in goal achievement, steadiness, responsibility, boldness and emotionality, tolerance, empathy, patience, ability to be on good terms with others, practicality, conscientiousness, astuteness with people around, a strong call of duty, vulnerability, sensitivity to other people's reactions, tough views, dependence on group support, strongwilled qualities, self-control, over-motivation, high liveliness, life satisfaction, ability to establish and maintain social contacts, emotional sensitivity, politeness. Remedial teachers require support and tend to be group-oriented. However, among comprehensive school teachers the following are predominating: sociability, openness, readiness to cooperate, superior intelligence characterized by quick-wittedness, high mental abilities, shrewdness, emotional stability, performance capability, emotional maturity, permanence of interests, diplomacy, timidity, dependence on others, cheerfulness, impulsiveness, leadership, high rule-consciousness, assertiveness in goal achievement, social boldness, activity, riskiness, reasoning, adequacy of judgment, practicality, suspiciousness, self-centeredness, straightforwardness, self-assurance, analyticity, criticality, group independence, self-reliance in decision making, strong-willed qualities, self-control, self-discipline, over-motivation, life satisfaction, ability to establish and maintain social contacts, stability, determination, boldness and flexibility.

Fig. 1.3. The characteristics of comparative analysis by patience value, altruism, sociability and activity orientations.

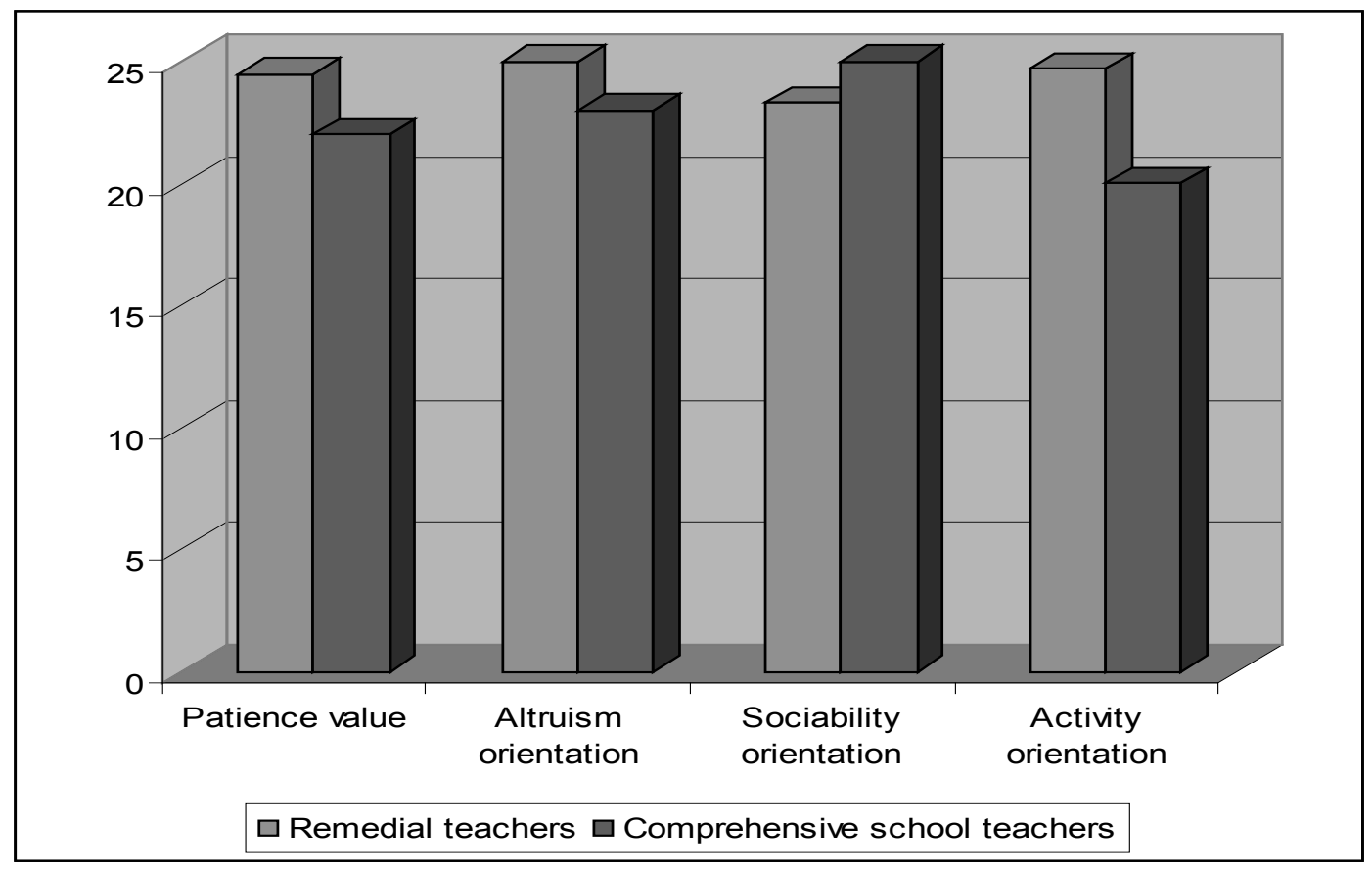

Source: Authors`research. 
According to the results of comparative analysis, it was determined that remedial teachers have a high level of patience value, altruism and activity orientations and they have a low level of sociability orientation. Instead, comprehensive school teachers have a high level of sociability orientation and they have a low level of patience value, altruism and activity orientations (see Fig. 1.3.).

According to the results of correlation analysis, among remedial teachers there was a direct correlation between characteristics of empathy (Factor I) and honesty value $(r=0,38)$; sensitivity, excessive care, empathy, tolerance and romance associated with sincere personality worry in attitude to others (see Fig. 1.4.).

Fig. 1.4. Correlation between empathy (Factor I) and honesty value.

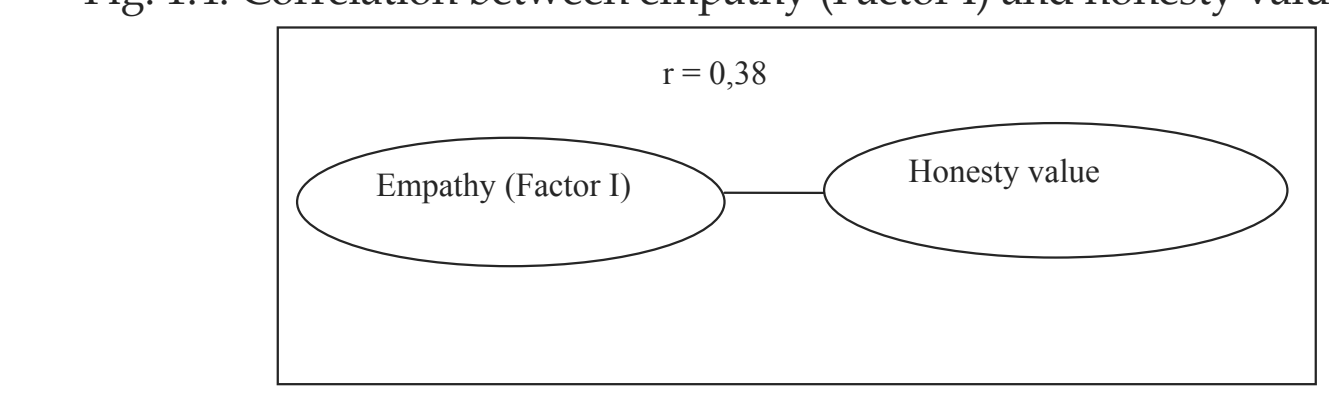

Source: Authors`research.

There is a converse correlation between characteristics of boldness (Factor $\mathrm{H}$ ) and a value of happiness for others $(\mathrm{r}=-0,37)$; riskiness, emotionality, impulsiveness reduce a drive of happiness for others. There is also a converse correlation between characteristics of orientation to work and a value of happiness for others $(\mathrm{r}=-0,35)$; activity orientation of a personality reduces a drive of happiness for others, since this person is more focused on achieving one's own career goals (see Fig. 1.5.).

Fig. 1.5. Correlation between a value of happiness for others with boldness (Factor $\mathrm{H}$ ) and orientation to work.

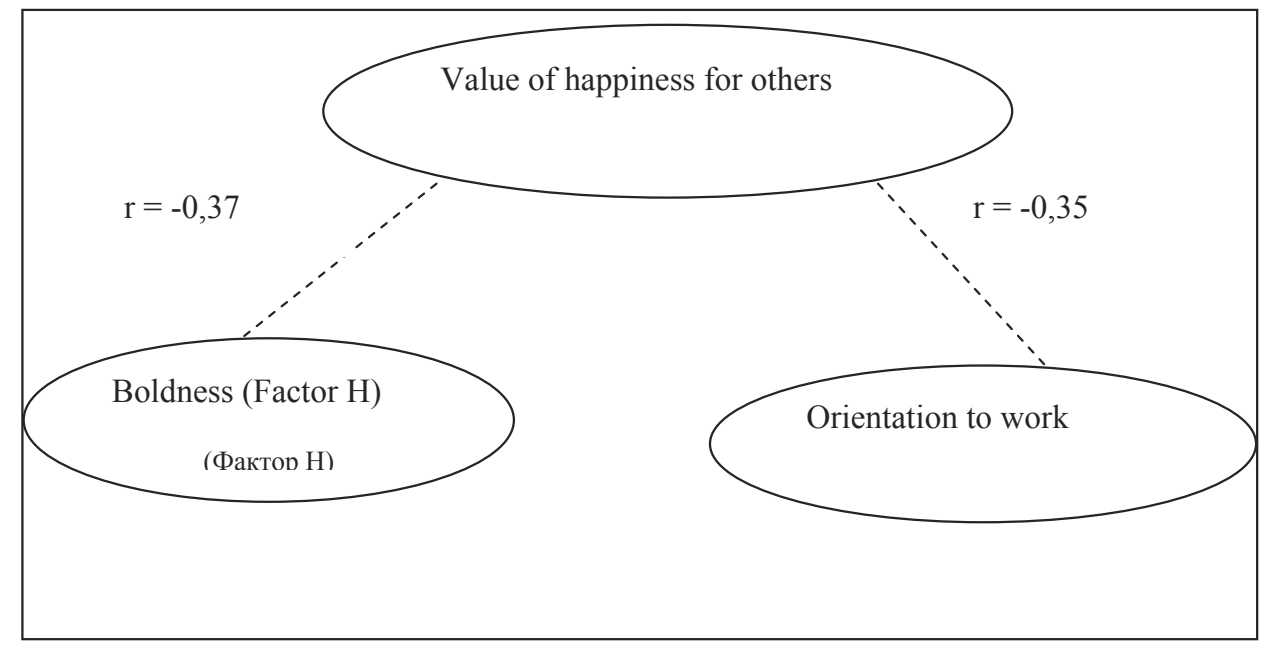

Source: Authors`research. 
Using multivariate analysis of empirical data obtained in the group of remedial teachers, three factors were distinguished as follows:

Factor 1 explains 17,9\% of variance and is called «Personality values and altruism orientation». It is represented by altruism orientation $(\mathrm{r}=0,634 \mathrm{p}=>0,7)$, entertainment value $(r=-0,775 p=>0,7)$, self-assurance value $(r=0,784 p=>0,7)$, high needs value $(r=0,900 p=>0,7)$, cheerfulness value $(r=0,944 p=>0,7)$, responsibility value $(r=0,832 p=>0,7)$, self-control value $(r=0,913 p=>0,7)$ and strong will value $(r=0,718 p=>0,7)$. The most factor loading is typical of cheerfulness value, and the least factor loading is peculiar to entertainment value. Humans of a high level of altruism orientation are self-assured, of high life needs, cheerful, responsible, independent in judgments but they also have a low self-control level.

Factor 2 explains $15,3 \%$ of variance and is called «Personality orientations». It is represented by altruism orientation $(\mathrm{r}=0,524 \mathrm{p}=>0,7)$, sociability orientation $(\mathrm{r}=$ $0,955 p=>0,7)$, self-assertion orientation $(r=-0,958 p=>0,7)$ and practice orientation $(r=0,608 p=>0,7)$. The most factor loading is typical of sociability orientation, and the least factor loading is peculiar to self-assertion orientation. A personality of altruism orientation is focused on communication with others and business problem solution, strives for perfect performance and is free of self-assertion.

Factor 3 explains 10,9\% of variance and is called «Personality values». It is represented by a value of interesting work $(\mathrm{r}=-0,825 \mathrm{p}=>0,7)$, freedom value $(\mathrm{r}=$ $0,888 \mathrm{p}=>0,7)$, responsibility value $(\mathrm{r}=-0,738 \mathrm{p}=>0,7)$ and altruism orientation $(\mathrm{r}=-0,787 \mathrm{p}=>0,7)$. The most factor loading is typical of freedom value, and the least factor loading is peculiar to a value of interesting work. A personality of a low altruism orientation level strives for (self-)independence and is of a lower call of duty level.

\section{SUMMARY}

Altruism is a motive to render assistance to anyone not consciously related to one's own selfish interests. Subjectively it manifests itself in sympathy, being oriented towards helping others. Altruism is opposed to selfishness which is incompatible with disinterested concern for the welfare of others and willingness to sacrifice personal interests to them. We determined that among comprehensive school teachers knowledge value (ability to expand one's education, views, personal culture, intellectual development) take first place, education value (breadth of knowledge, considerable personal culture) take second place, self-assurance value (inner harmony, freedom from self-contradictions and doubts) take third place with breadth of views value (skill to understand another's point of view, respect other tastes, customs and habits). Among remedial teachers tolerance value (to other people's opinions and views, ability to forgive others their mistakes) takes first place, development value (self-perfection, permanent physical and spiritual improvement) takes second place, strong will value (skill to insist on one's own way, to face difficulties) takes third place with independence value (ability to act on one's authority and in a determined way). Remedial teachers 
have a high level of patience value, altruism and activity orientations and they have a low level of sociability orientation. However, comprehensive school teachers have a high level of sociability orientation and they have a low level of patience value, altruism and activity orientations.

\section{REFERENCES}

Adolph, V. A. (1998). Профессиональная компетентность современного учителя: монография [Professional qualifications of a contemporary teacher: monograph]. Krasnoyarsk: КрГУ.

Andreyeva, H. М. (1998). Социальная психология [Social psychology]. Moscow: Аспект-Пресс.

Aronson, Е. (2002). Социальная психология. Психологические законы поведения человека в социчме [Social psychology. Psychological laws of human behaviour in society]. Moscow: Прайм-Еврознак.

Bass, B. M. (1967). Social behaviour and the orientation inventory: A review. Psychological Bulletin, 68, pp. $260-292$.

Batson, C. D. (2011). Altruism in Humans. New York: Oxford University Press.

Cattell, R. B. (1950). Personality: A systematic, theoretical, and factual study. New York: McGraw Hill.

Hapon, N. P. (2008). Соціальна психологія: Навчальний посібник [Social psychology: Manual]. Lviv: Видавничий центр ЛНУ ім. Івана Франка.

Heckhausen, H., \& Heckhausen, J. (2008). Motivation and Action. Cambridge, UK: Cambridge University Press.

Karylowski, J. J. (1982). O dwoch typach altruizmu: Badania nad endocentrycznymi i eqzocentrycznymi zrodlami bezinteresownych dzialan na rzecz innych ludzi. [On the two types of altruism: Studies on endocentric and exocentric sources of prosocial behavior]. Wroclaw: Zaklad Narodowy im. Ossolinskich.

Kolupayeva, А. А. (2009). Інклюзивна освіта: реалї̈ та перспективи: монографія [Inclusive education: realias and perspectives: monograph]. Куiv: Самміт-Книга.

Potyomkina, O. F. (2005). Психология потребностей и мотиваиия персонала [Psychology of needs and staff motivation]. Kharkiv: Гуманитарный центр.

Schwartz, Sh. H., \& Boehnke, K. (2004). Evaluating the structure of human values with confirmatory factor analysis. Journal of Research in Personality, 38, pp. 230 - 255. 